Article

\title{
Selenol-Based Nucleophilic Reaction for the Preparation of Reactive Oxygen Species-Responsive Amphiphilic Diblock Copolymers
}

\author{
Xiaowei An, Weihong Lu, Jian Zhu*(D), Xiangqiang Pan * ${ }^{\mathbb{D}}$ and Xiulin Zhu \\ Jiangsu Key Laboratory of Advanced Functional Polymer Design and Application, College of Chemistry, \\ Chemical Engineering and Materials Science, Soochow University, Suzhou 215123, China; \\ 20164009027@stu.suda.edu.cn (X.A.); luweihong@suda.edu.cn (W.L.); xlzhu@suda.edu.cn (X.Z.) \\ * Correspondence: chemzhujian@suda.edu.cn (J.Z.); panxq@suda.edu.cn (X.P.); Tel.: +86-512-6588-0726 (J.Z.); \\ $+86-512-6588-3343$ (X.P.)
}

Received: 15 February 2019; Accepted: 5 May 2019; Published: 8 May 2019

\begin{abstract}
Selenide-containing amphiphilic copolymers have shown significant potential for application in drug release systems. Herein, we present a methodology for the design of a reactive oxygen species-responsive amphiphilic diblock selenide-labeled copolymer. This copolymer with controlled molecular weight and narrow molecular weight distribution was prepared by sequential organoselenium-mediated reversible addition fragmentation chain transfer (Se-RAFT) polymerization and selenol-based nucleophilic reaction. Nuclear magnetic resonance (NMR) and matrix-assisted laser desorption/ionization time-to-flight (MALDI-TOF) techniques were used to characterize its structure. Its corresponding nanomicelles successfully formed through self-assembly from the copolymer itself. Such nanomicelles could rapidly disassemble under oxidative conditions due to the fragmentation of the $\mathrm{Se}-\mathrm{C}$ bond. Therefore, this type of nanomicelle based on selenide-labeled amphiphilic copolymers potentially provides a new platform for drug delivery.
\end{abstract}

Keywords: RAFT; selenol; amphiphilic polymer; drug delivery

\section{Introduction}

Compared with sulfur, selenium shows versatile properties owing to its larger atomic radius and relatively lower electronegativity [1]. Selenium-containing polymers have attracted a great deal of attention in recent years and have been widely used as photoelectric materials, adaptive materials, and biomedical materials [2,3]. Selenophene polymers have been considered to be effective photoelectric materials which may be widely used in solar cells, molecular switches, thin film transistors, etc. [4-12]. Diselenide-containing adaptive materials were successfully incorporated in the fabrication process under very mild conditions to achieve self-healing properties [13-16]. Selenium-containing polymers show versatile responsive behaviors to multiple stimuli, such as oxidation, reduction, and irradiation [17-23], which makes them potentially useful bio-building blocks. Traditional methods for preparing selenium-containing polymers used step growth polymerization [24-28], radical polymerization [29-34], and ring-opening polymerization [35-37], and our group successfully developed organoselenium-mediated controlled radical polymerization (Se-RAFT) to prepare selenium-containing polymers with both controlled molecular weight and narrow molecular weight distribution [38]. Subsequently, the application of selenol-based nucleophilic substitution and Se-Michael addition reactions for polymer chain end modification was presented [39], so that many functional groups could be introduced to the selenium-containing polymers. Herein, we reported a new application of selenol-based nucleophilic reaction for the design of a reactive oxygen species-responsive 
amphiphilic diblock copolymer. Firstly, the diselenocarbonate-end capped polystyrenes with different molecular weights (MWs) were prepared through the organoselenium-mediated radical polymerization of styrene (St). After aminolysis of diselenocarbonate with hexylamine, nucleophilic attack of the exposed selenol to poly(ethylene glycol) methyl ether methacrylate (PEGMA) gave a selenide-labeled diblock copolymer (denoted as PS-Se-b-PEGMA; see Scheme 1). PS-Se-b-PEGMA is able to form micellar aggregates in water which are disassembled in oxidation conditions.
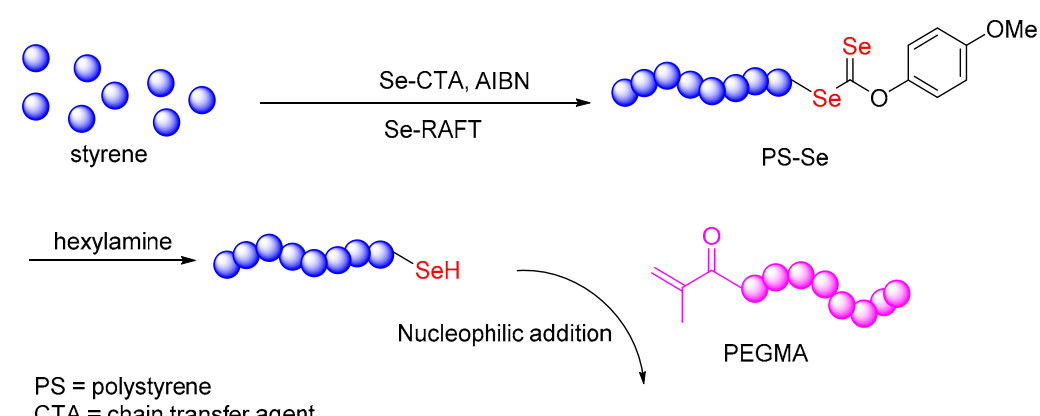

$\mathrm{CTA}=$ chain transfer agent

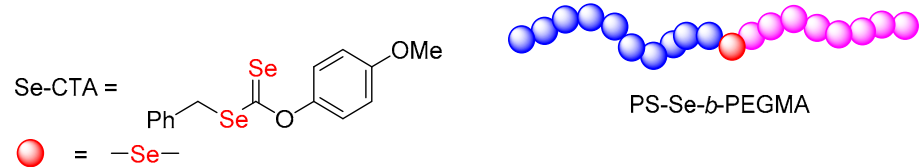

Scheme 1. Selenol-based nucleophilic reaction as a novel reaction forming amphiphilic diblock copolymers.

\section{Experimental Section}

\subsection{Materials}

Styrene was purchased from Shanghai Chemical Reagents Co. Ltd., Shanghai, China, and purified before use. PEGMA $\left(M_{n}=300,500\right.$, and $1000 \mathrm{~g} \mathrm{~mol}^{-1}$; Aldrich) was passed through an alumina column to remove the inhibitor. After that, it was dried with calcium hydride, then distilled under reduced pressure and kept in a refrigerator below $0{ }^{\circ} \mathrm{C}$. 2,2'-Azoisobutyronitrile (AIBN, 98\%) was recrystallized from ethanol and then stored in a refrigerator at $4{ }^{\circ} \mathrm{C}$. Se-benzyl $\mathrm{O}$-(4-methoxyphenyl) carbonodiselenoate (Se-CTA) was synthesized according to a previously reported method [33]. Tributylphosphane $\left(\mathrm{Bu}_{3} \mathrm{P}, 98 \%\right)$ was purchased from Adamas Reagent Ltd, Shanghai, China. Dialysis bags (molecular weight cutoff: $1000 \mathrm{Da}$ ) were purchased from Sinopharm Chemical Reagent Co. Ltd., Shanghai, China. Tetrahydrofuran (THF), N,N-dimethylformamide (DMF), methanol $(\mathrm{MeOH})$, and other chemicals were purchased from Shanghai Chemical Reagents Co. Ltd. Shanghai, China and used without further treatment. Doxorubicin hydrochloride (DOX.HCl, 99\%) was purchased from Sigma, Shanghai, China.

\subsection{Characterization}

The number-average molecular weight $\left(M_{n}\right)$ and molecular weight distribution $(\nexists)$ of the resulting polymers were determined by a TOSOH HLC-8320 size exclusion chromatograph (SEC) equipped with a TSKgel SuperMultiporeHZ-N column (3) $(4.6 \times 150 \mathrm{~mm})$ at $40{ }^{\circ} \mathrm{C}$. Tetrahydrofuran served as the eluent with a flow rate of $0.35 \mathrm{~mL} \mathrm{~min}^{-1}$. SEC samples were injected using a TOSOH HLC-8320 SEC plus autosampler. The molecular weights were calibrated with polystyrene (PS) standards. ${ }^{1} \mathrm{H}$ $(300 \mathrm{MHz})$ NMR spectra were recorded on a Bruker Avance 300 spectrometer. Chemical shifts are presented in parts per million $(\delta)$ relative to $\mathrm{CHCl}_{3}$ (7.26 ppm in $\left.{ }^{1} \mathrm{H} \mathrm{NMR}\right)$. Transmission electron microscopy (TEM) was performed with a HITACHI HT7700 microscope operating at a $120-\mathrm{kV}$ accelerating voltage. The fluorescence emission spectra (FL) were obtained on a HITACHI F-4600 fluorescence spectrophotometer at room temperature. Hydrodynamic diameter $\left(D_{\mathrm{h}}\right)$ was determined by dynamic light scattering (DLS) using a Brookhaven NanoBrook 90Plus PALS instrument at $25^{\circ} \mathrm{C}$ 
with a scattering angle of $90^{\circ}$. Fourier transform infrared spectroscopy (FT-IR) was recorded with the Bruker TENSOR 27 FT-IR instrument using the conventional KBr pellet method. The elemental composition of the surfaces was measured with X-ray photoelectron spectroscopy (XPS) (Thermo Fisher Scientific ESCALAB 250 XI, Al KR source).

\subsection{Typical Procedure of Organoselenium-Mediated Controlled Radical Polymerization}

A dry 10-mL ampule was filled with styrene $(8.0 \mathrm{~mL}, 80 \mathrm{mmol})$, Se-benzyl O-(4-methoxyphenyl) carbonodiselenoate (Se-CTA) $(0.6147 \mathrm{~g}, 1.6 \mathrm{mmol})$, and AIBN $(0.0788 \mathrm{~g}, 0.48 \mathrm{mmol})$. The solution was degassed using the standard freeze-pump-thaw method (at least 3 cycles). The ampule was flame-sealed and placed into an oil bath, which was thermoset at the desired temperature. At timed intervals, the ampule was immersed into iced water and then opened. The contents were dissolved in $3 \mathrm{~mL}$ of tetrahydrofuran (THF) and precipitated into $400 \mathrm{~mL}$ of methanol. Carbonodiselenoate-labeled polystyrene (PS-Se) was obtained by filtration and then dried to constant weight at room temperature under vacuum. The conversion of styrene was gravimetrically determined.

\subsection{Typical Procedure of Selenol-Based Nucleophilic Addition of PS-Se to PEGMA}

Without additional notes, a typical procedure for optimization of reaction time is given below as an example. A dry 5-mL ampule was filled with PS-Se-1 $\left(M_{\mathrm{n}, \mathrm{SEC}}=1900 \mathrm{~g} \mathrm{~mol}^{-1}, 95 \mathrm{mg}, 0.059 \mathrm{mmol}\right)$, PEGMA950 $\left(M_{\mathrm{n}}=950 \mathrm{~g} \mathrm{~mol}^{-1}, 0.59 \mathrm{~g}, 0.59 \mathrm{mmol}\right)$, and DMF $(2.0 \mathrm{~mL})$ with a stir bar. After being thoroughly bubbled with argon for $15 \mathrm{~min}$ to eliminate the dissolved oxygen, n-hexylamine $(30 \mu \mathrm{L})$ was added. Then, the ampule was flame-sealed immediately. After stirring for $1 \mathrm{~d}$ at $60^{\circ} \mathrm{C}$, the solution was precipitated into $100 \mathrm{~mL}$ of methanol. The polymer was obtained by filtration and then dried to constant weight at room temperature under vacuum.

\subsection{Fabrication of PS-Se-b-PEGMA Micelles}

PS-Se-b-PEGMA (2 mg) was dissolved in DMF (2 mL), and then deionized water $(0.3 \mathrm{~mL})$ was added to the solution using a syringe pump at the rate of $0.2 \mathrm{~mL} \mathrm{~h}^{-1}$ at room temperature. After addition of the water, the suspension was stocked for 1 day to stabilize the aggregates. Then, the suspension was dialyzed in a dialysis bag (molecular weight cutoff: $1000 \mathrm{Da}$ ) against deionized water for at least $24 \mathrm{~h}$ to remove DMF. After dialysis, the suspension was added to deionized water until the volume increased to $2 \mathrm{~mL}$ with a concentration of $1 \mathrm{mg} \mathrm{mL}^{-1}$ for further tests.

\subsection{Chemical Oxidation of PS-Se-b-PEGMA Micelles by $\mathrm{H}_{2} \mathrm{O}_{2}$}

In brief, $0.5 \mathrm{~mL}$ of PS-Se- $b$-PEGMA micelle suspension was kept in a 1-mL ampule and then placed into $\mathrm{H}_{2} \mathrm{O}_{2}$ solution (33 mM). After stirring for $5 \mathrm{~h}$, the micelle suspension was freeze-dried for TEM studies.

\subsection{In Vitro Cytotoxicity Study of the Micelles}

The samples were disinfected under ultraviolet light, and then five groups of extracts $(2,4,6,8$, and $10 \mathrm{mg} \mathrm{mL}^{-1}$ ) were prepared. The blank group (culture medium) and the control group (culture medium and cells) were set up to compare with the experimental group. NIH-3T3 cells were inoculated on 96-well plates at a density of $8 \times 10^{4} \mathrm{~mL}^{-1}\left(8 \times 10^{3}\right.$ well $\left.{ }^{-1}\right)$. Cells were cultured in incubators (at $37^{\circ} \mathrm{C}$ and $5 \%$ carbon dioxide) to become adhered to the 96 -well plates. After $24 \mathrm{~h}$, the medium was removed and the extract was added to culture. Then, $24 \mathrm{~h}$ later, the extract was removed and $10 \mu \mathrm{L}$ CCK-8 solution and $90 \mu \mathrm{L}$ culture medium were added to each pore. Then, cells were incubated at $37^{\circ} \mathrm{C}$ for $1 \mathrm{~h}$. A microplate reader was used to measure the absorbance of the sample at $450 \mathrm{~nm}$. 


\subsection{Drug Loading}

The following process was carried out in the dark. A mixture of $5.0 \mathrm{mg}$ DOX. $\mathrm{HCl}$ and $3.6 \mu \mathrm{L}$ of triethylamine (TEA) in $1.0 \mathrm{~mL}$ of dimethyl sulfoxide (DMSO) was added to a 2-mL ampule. After stirring overnight, excess TEA was removed by rotary evaporation to give the hydrophobic DOX solution. Then, $4 \mathrm{~mL}$ of PBS solution ( $50 \mathrm{mM}, \mathrm{pH} 7.4)$ was added dropwise to the mixture of copolymer in DMF $\left(1.0 \mathrm{~mL}, 1 \mathrm{mg} \mathrm{mL}^{-1}\right)$ and DOX base solution $\left(50 \mu \mathrm{L}, 5.0 \mathrm{mg} \mathrm{mL}^{-1}\right)$ with stirring at room temperature. Afterwards, in order to remove both unencapsulated DOX and the organic solvent, the mixture was dialyzed against PBS solution ( $50 \mathrm{mM}, \mathrm{pH} 7.4)$ for $24 \mathrm{~h}$.

The amount of DOX was determined by fluorescence (FL4600) measurement (excitation at $480 \mathrm{~nm}$ ). First, a calibration curve was obtained by measuring the fluorescence intensity of different concentration DOX/DMSO solutions. Second, the fluorescence intensity of DOX-loaded micelles dissolved in DMSO was analyzed. The amount of DOX loaded in the micelles could be determined using the calibration curve.

The drug loading content (DLC) and drug loading efficiency (DLE) were calculated using the following formulas:

DLC $($ wt. $\%)=($ weight of loaded drug $/$ weight of $($ polymer + loaded drug $)) \times 100 \%$

$\operatorname{DLE}($ wt. $\%)=($ weight of loaded drug $/$ weight of drug in feed $) \times 100 \%$

\subsection{Oxidation-Responsive Drug Release}

In brief, $33 \mathrm{mM} \mathrm{H} \mathrm{H}_{2} \mathrm{O}_{2}$ was added into freshly prepared self-assembled solution $(1.0 \mathrm{~mL})$ of PS-Se-1-b-PEGMA 950 in PBS. The reaction mixture was stirred at $25^{\circ} \mathrm{C}$ for $3 \mathrm{~h}$.

Fluorescence spectrophotometry was then used to monitor the change in fluorescence intensity of the micelle solution.

\section{Results and Discussion}

\subsection{Organoselenium-Mediated Controlled Radical Polymerization}

The diselenocarbonate-end capped polymers were prepared through the organoselenium-mediated polymerization of styrene (St) according to our previous reports [33]. Two polymers, PS-Se-1 and PS-Se-2, with different molecular weights and narrow molecular weight distribution $(<1.20)$ were prepared, as detailed in Table 1 . The structure of PS-Se- 1 was characterized by ${ }^{1} \mathrm{H}$ NMR. As shown in Figure 1, the signals at $\delta 3.78 \mathrm{ppm}\left(3 \mathrm{H}, I_{3.78}=3.00\right)$ were ascribed to the protons of the methoxy group $(-\mathrm{OMe})$, and the signals around $\delta 4.50 \mathrm{ppm}\left(1 \mathrm{H}, \mathrm{I}_{4.43-4.68}=1.06\right)$ were ascribed to the protons of CH-Se. The signals at around $\delta 7.00 \mathrm{ppm}\left(5 \mathrm{H}, I_{6.60-7.11}=92.1\right)$ were ascribed to the protons of the phenyl group. Thus, the molecular weight $\left(M_{\mathrm{n}, \mathrm{NMR}}\right)$ can be calculated to be $2100 \mathrm{~g} \mathrm{~mol}^{-1}$ by the equation $M_{\mathrm{n}}$, NMR $=104 \times[(92.1-9) / 5]+91+295$. The polymers were also measured by using SEC with coupled refractive index (RI) and UV detectors (Figure 2). The two curves almost coincide, and the molecular weight $\left(M_{n, G P C}=1900 \mathrm{~g} \mathrm{~mol}^{-1}\right)$ was close to the value obtained by ${ }^{1} \mathrm{H}$ NMR. All evidence proved the high chain end functionality of the diselenocarbonate-ended polystyrene (PS), which ensured further chain end modification. 


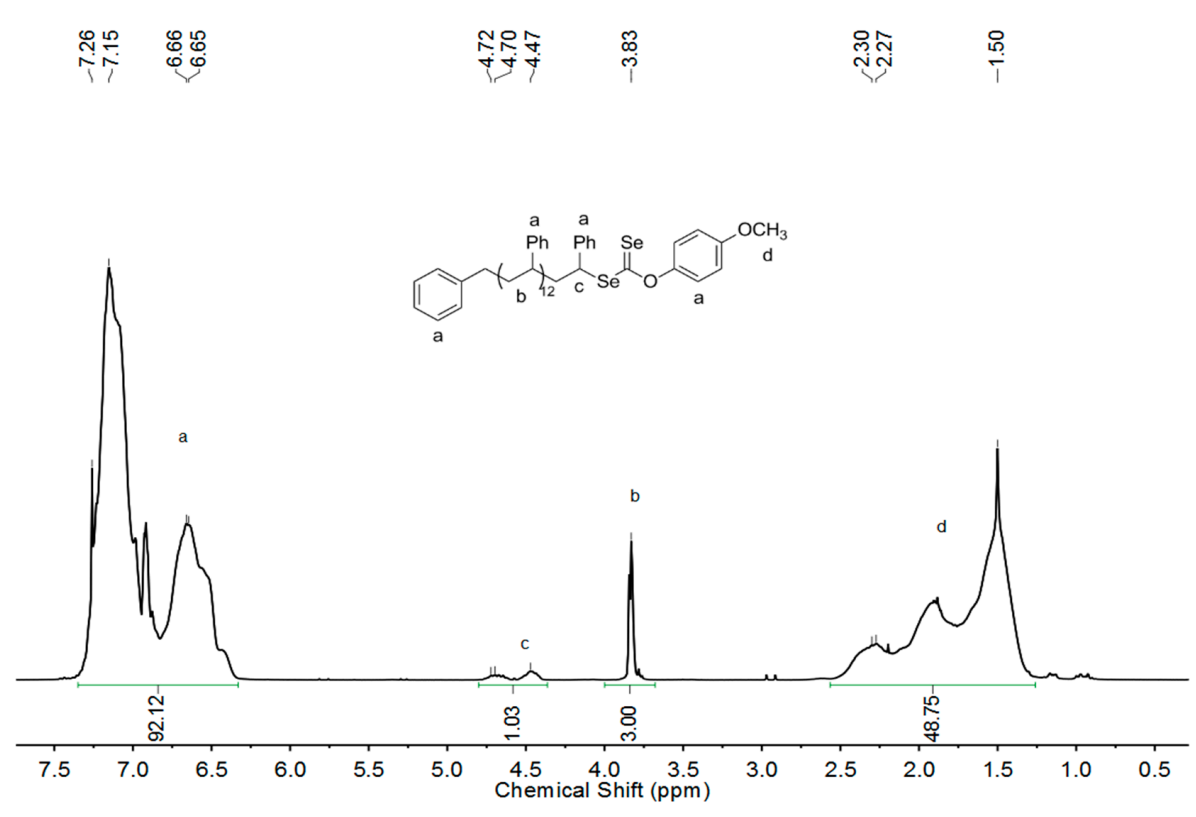

Figure 1. ${ }^{1} \mathrm{H} \mathrm{NMR}$ (in $\mathrm{CDCl}_{3}$ ) spectra of PS-Se-1.

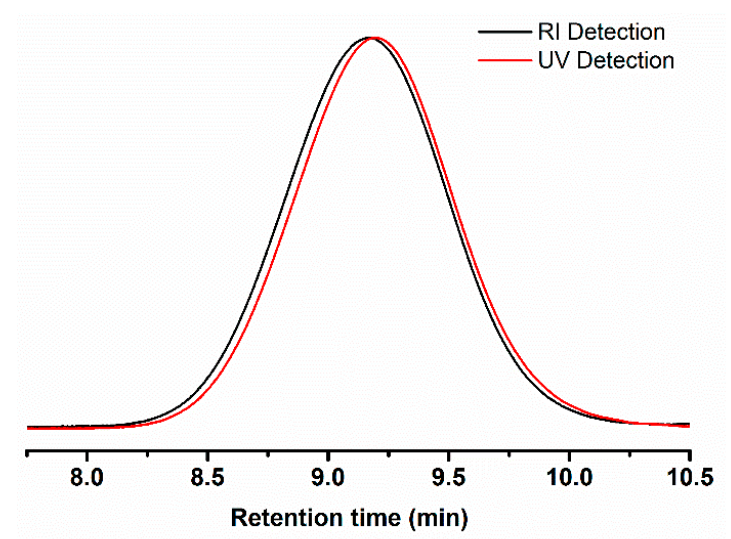

Figure 2. SEC curves of PS-Se- $1\left(M_{n}, \mathrm{SEC}=1900 \mathrm{~g} \mathrm{~mol}^{-1}, Ð=1.20\right)$ measured by RI and UV detection at the wavelength of $340 \mathrm{~nm}$.

Table 1. Polymerization of St with the molar ratio $[\mathrm{St}]_{0}:[\mathrm{Se}-\mathrm{CTA}]_{0}:[\mathrm{AIBN}]_{0}=50: 1: 0.3$ in bulk at $70{ }^{\circ} \mathrm{C}$.

\begin{tabular}{|c|c|c|c|c|c|c|}
\hline Entry & Time (h) & Conv. $(\%)$ & $\begin{array}{l}M_{\mathrm{n}, \mathrm{SEC}}{ }^{a} \\
\left(\mathrm{~g} \mathrm{~mol}^{-1}\right)\end{array}$ & $\begin{array}{c}M_{\mathrm{n}, \mathrm{th}}{ }^{b} \\
\left(\mathrm{~g} \mathrm{~mol}^{-1}\right)\end{array}$ & $\begin{array}{l}M_{\mathrm{n}, \mathrm{NMR}}{ }^{c} \\
\left(\mathrm{~g} \mathrm{~mol}^{-1}\right)\end{array}$ & $\boxplus^{a}$ \\
\hline 1 (PS-Se-1) & 2 & 27.6 & 1900 & 1800 & 2100 & 1.20 \\
\hline 2 (PS-Se-2) & 4 & 37.5 & 4200 & 4200 & 4400 & 1.17 \\
\hline
\end{tabular}

${ }^{a} M_{\mathrm{n}, \mathrm{SEC}}$ and $\boxminus$ were determined by size exclusion chromatography (SEC; using THF as eluent, $1 \mathrm{~mL} \mathrm{~min}^{-1}, 40^{\circ} \mathrm{C}$ ) using polystyrene calibration. ${ }^{b}$ Theoretical molecular weight. ${ }^{c}$ Molecular weight determined by ${ }^{1} \mathrm{H}$ NMR.

\subsection{Reaction Condition Optimization of Selenol-Based Nucleophilic Reaction}

As in our previous reports, diselenocarbonate was expected to be converted to selenol by amine compounds [39]. In the present work, after the rapid aminolysis of PS-Se-1 $\left(M_{\mathrm{n}}, \mathrm{SEC}=1900 \mathrm{~g} \mathrm{~mol}^{-1}\right)$ by $n$-hexyl amine, the corresponding selenol reacted with PEGMA ${ }_{950}\left(M_{n}=950 \mathrm{~g} \mathrm{~mol}^{-1}\right)$ to make the block copolymers (Scheme 2). We initiated our studies by examining the effect of time on selenol-based nucleophilic reaction. The results are presented in Table 2. Screening experiments indicated that moderate conversion of PS-Se-1 could be obtained after four days (entries 1, 2, 3, and 4). An increase in temperature from $25^{\circ} \mathrm{C}$ to $60^{\circ} \mathrm{C}$ resulted in the increase of the conversion of PS-Se- 1 from $22.4 \%$ to $50 \%$ (Table 2, entry 5). It was already found that $\mathrm{Bu}_{3} \mathrm{P}$ could act as a reducing agent to prevent 
oxidative coupling of selenol. Without $\mathrm{Bu}_{3} \mathrm{P}$, the conversion of PS-Se-1 dropped to $14.6 \%$ (Table 2, entry 6). $\mathrm{Bu}_{3} \mathrm{P}$ also acts as a catalyst for the subsequent selenol-Michael addition reaction. Consequently, no more catalyst, such as DBU and $\mathrm{Et}_{3} \mathrm{~N}$, was needed to be added to this system (entries 7 and 8) [1]. Lastly, the effect of molar ratio on selenol-based nucleophilic reaction was examined. The reaction became more smooth as the amount of PEGMA (entries 9 and 10) increased. When the molar ratio of PS-Se-1:PEGMA = 1:10, the reaction reached the highest conversion rate of about $85 \%$ after separation. In contrast, the higher molar ratio of PS-Se-1:PEGMA (1:50) resulted in an extremely viscose solution, which may prevent further reaction. Moreover, purification loss also decreases the product yield.

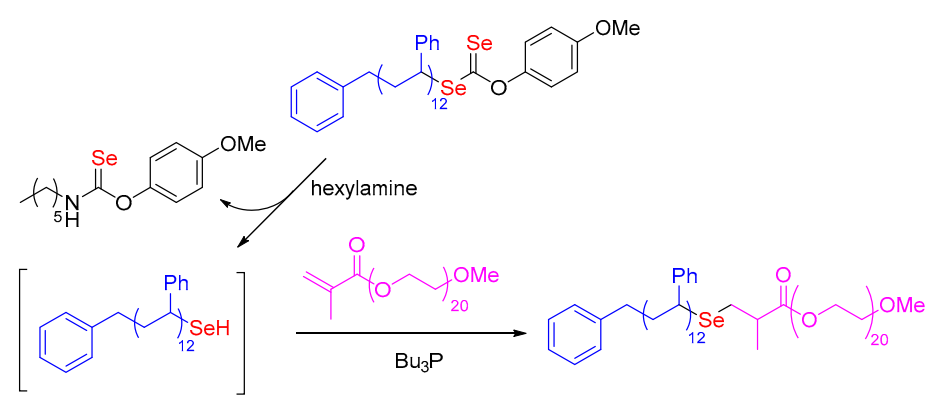

Scheme 2. Reaction route of aminolysis of diselenocarbonate organic compound with hexylamine and then selenol-based nucleophilic reaction with PEGMA950.

Table 2. Optimization studies for selenol-based nucleophilic reaction of PS-Se-1 with PEGMA $950{ }^{a}$.

\begin{tabular}{|c|c|c|c|c|c|c|}
\hline Entry & Time (d) & Catalyst & $\mathbf{R}^{b}$ & Conv. $^{c}(\%)$ & $M_{\mathrm{n}, \mathrm{SEC}}{ }^{d}\left(\mathrm{~g} \mathrm{~mol}^{-1}\right)$ & $\oplus^{d}$ \\
\hline 1 & 1 & - & $1: 1$ & 24.8 & 3100 & 1.14 \\
\hline 2 & 2 & - & $1: 1$ & 23.0 & 3400 & 1.11 \\
\hline 3 & 4 & - & $1: 1$ & 50.0 & 3500 & 1.12 \\
\hline 4 & 6 & - & $1: 1$ & 31.7 & 3400 & 1.11 \\
\hline $5^{e}$ & 4 & - & $1: 1$ & 22.4 & 3700 & 1.10 \\
\hline $6^{f}$ & 4 & - & $1: 1$ & 14.6 & 3700 & 1.11 \\
\hline 7 & 4 & $10 \% \mathrm{DBU}$ & $1: 1$ & 25.9 & 3500 & 1.10 \\
\hline 8 & 4 & $10 \% \mathrm{Et}_{3} \mathrm{~N}$ & $1: 1$ & 22.8 & 3400 & 1.11 \\
\hline 9 & 4 & - & $1: 2$ & 64.0 & 3500 & 1.11 \\
\hline 10 & 4 & - & $1: 10$ & 85.0 & 3700 & 1.11 \\
\hline 11 & 4 & - & $1: 50$ & 46.0 & 3500 & 1.12 \\
\hline
\end{tabular}

${ }^{a}$ The reaction was carried out at $60^{\circ} \mathrm{C}$ with $\mathrm{Bu}_{3} \mathrm{P} .{ }^{b}$ The ratio of PS-Se- 1 with PEGMA ${ }_{950}{ }^{c}$ Conversion of PS-Se-1 determined after separation by NMR analysis with tetramethylsilane (TMS) as the internal standard for chemical shifts. ${ }^{d} \oslash$ was determined by SEC (THF as eluent, $1 \mathrm{~mL} \mathrm{~min}^{-1}, 40^{\circ} \mathrm{C}$ ) using polystyrene calibration. ${ }^{e}$ The reaction was carried out at $25^{\circ} \mathrm{C}$ with $\mathrm{Bu}_{3} \mathrm{P}^{.}{ }^{f}$ The reaction was carried out at $60^{\circ} \mathrm{C}$ without $\mathrm{Bu}_{3} \mathrm{P}$.

\subsection{Selenol-Based Nucleophilic Reaction of PS-Se-1 and PEGMAs with Different Molecular Weights}

After studying reaction condition optimization for selenol-based nucleophilic reaction of PS-Se-1 with PEGMA950, PEGMAs with different molecular weights were examined. The results are listed in Table 3. PS-Se-1 reacted efficiently with PEGMA and the conversion rate of PS-Se-1 with PEGMA 320 peaked at 95.4\%, and the conversion rate of PS-Se-1 decreased with the increase of molecular weight of PEGMA. The $M_{n}$ of copolymers was determined by SEC. As shown in Figure 3, the curves shifted significantly after the nucleophilic reaction, which evidenced the successful modification of PEGMA at the end of PS-Se-1. In the ${ }^{1} \mathrm{H}$ NMR spectra, the proton signals of the corresponding vinyl shifted from 6.10 and $5.54 \mathrm{ppm}$ to 2.57 and $2.49 \mathrm{ppm}$, and the proton signals of $\mathrm{CH}$ groups close to Se shifted from 4.70 and $4.47 \mathrm{ppm}$ to $2.84 \mathrm{ppm}$, indicating a complete conversion of PEGMA (Figure 4). Also, MALDI-TOF mass spectrometry was used to further characterize the structure of the copolymer. As shown in Figure 5, the main population at the isotropic peak at $2340.428 \mathrm{~m} / \mathrm{z}$ matched the theoretical calculation well $(2340.152 \mathrm{~m} / \mathrm{z})$. Furthermore, two main sequence peaks are very close to the styrene (104.15 $\left.\mathrm{g} \mathrm{mol}^{-1}\right)$ and $\mathrm{CH}_{2} \mathrm{CH}_{2} \mathrm{O}\left(44.03 \mathrm{~g} \mathrm{~mol}^{-1}\right)$ units. All the evidence indicated the efficiency of this reaction. 


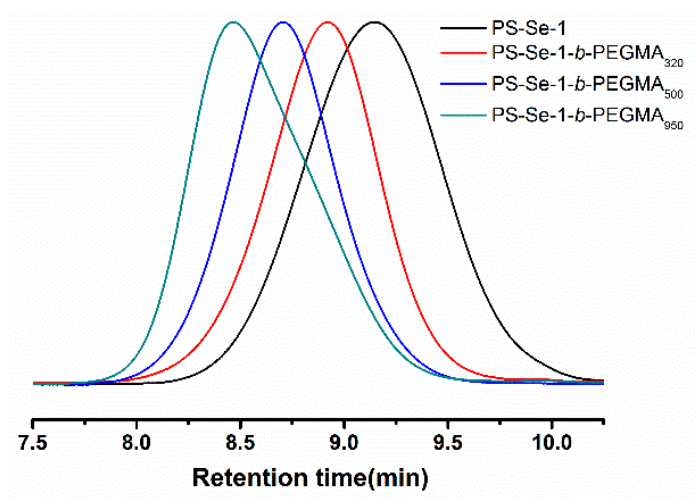

Figure 3. SEC curves of PS-Se-1 $\left(M_{n, S E C}=1900 \mathrm{~g} \mathrm{~mol}^{-1}, \emptyset=1.14\right)$, PS-Se-1- $b$-PEGMA $320\left(M_{n, S E C}=2700\right.$ $\left.\mathrm{g} \mathrm{mol}^{-1}, Ð=1.09\right)$, PS-Se-1- $b$-PEGMA ${ }_{500}\left(M_{\mathrm{n}, \mathrm{SEC}}=3200 \mathrm{~g} \mathrm{~mol}^{-1}, Ð=1.09\right)$, and PS-Se-1- $b$-PEGMA 950 $\left(M_{\mathrm{n}, \mathrm{SEC}}=3700 \mathrm{~g} \mathrm{~mol}^{-1}, Ð=1.11\right)$.
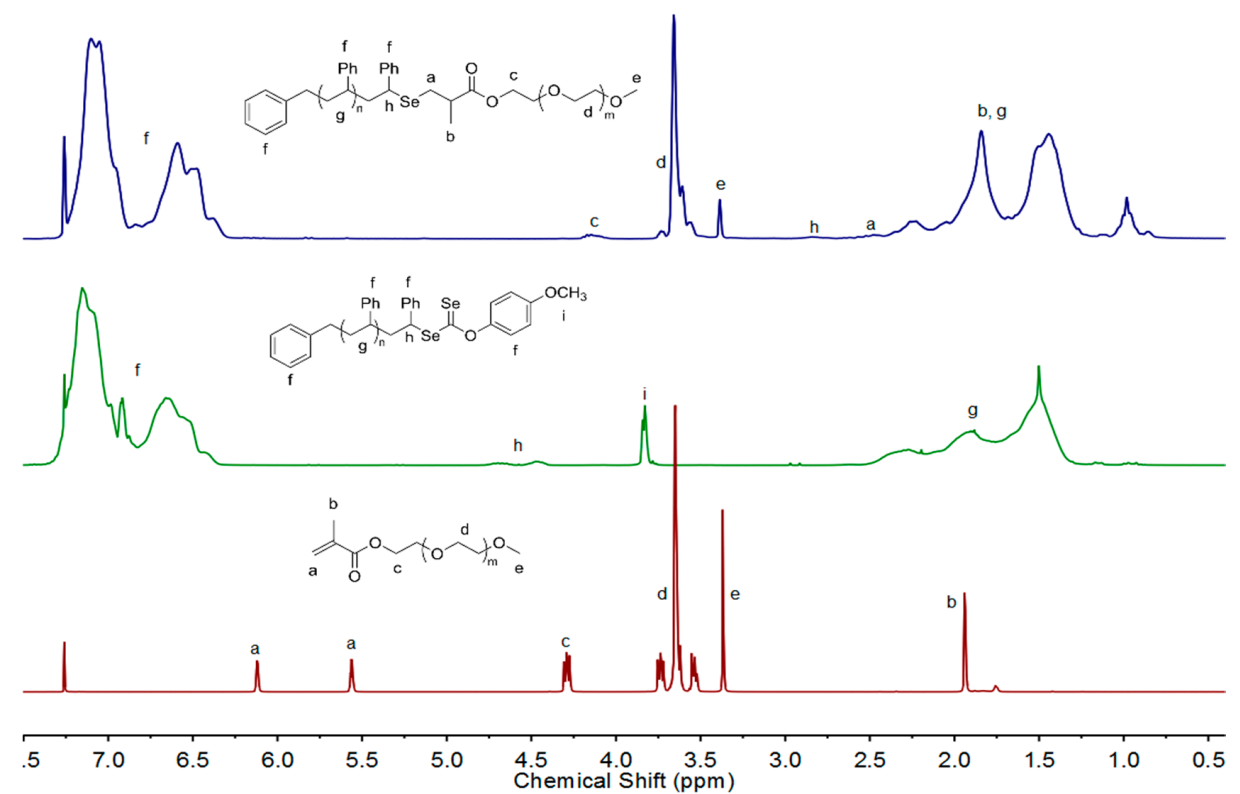

Figure 4. ${ }^{1} \mathrm{H}$ NMR (in $\left.\mathrm{CDCl}_{3}\right)$ spectrum of PS-Se-1- $b$-PEGMA $320\left(M_{\mathrm{n}, \mathrm{SEC}}=2700 \mathrm{~g} \mathrm{~mol}^{-1}, Ð=1.09\right)$.

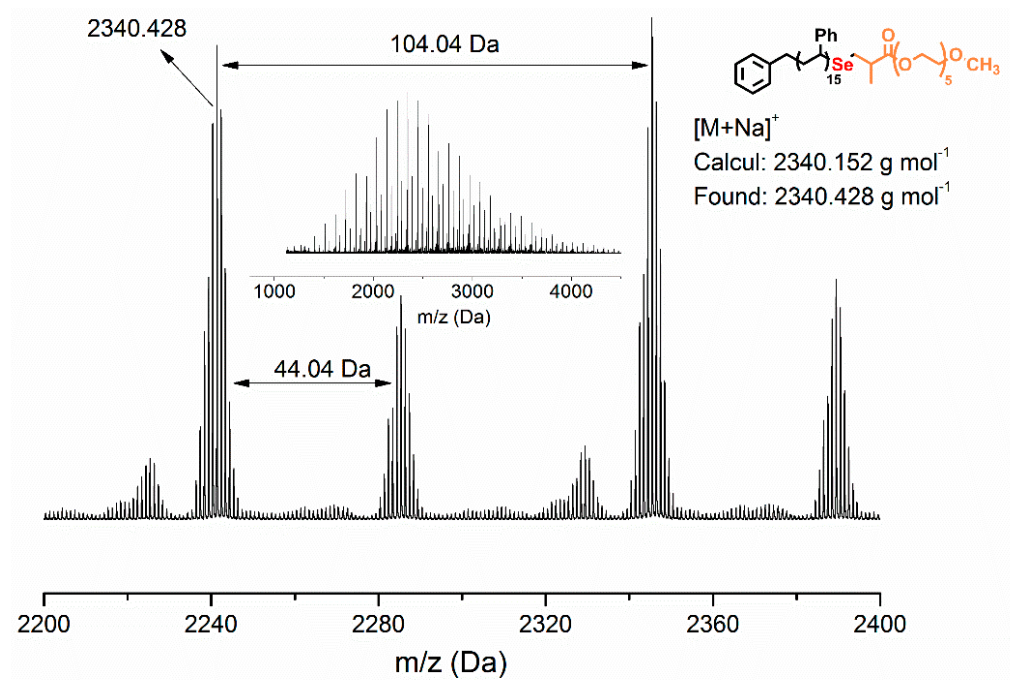

Figure 5. Mass spectra of PS-Se-1- $b$-PEGMA $320\left(M_{n, S E C}=2700 \mathrm{~g} \mathrm{~mol}^{-1}, Ð=1.09\right)$. 
Table 3. Selenol-based nucleophilic reaction of PS-Se with different molecular weight PEGMAs.

\begin{tabular}{|c|c|c|c|c|}
\hline Entry & PEGMA (g mol-1) & Conv. $(\%)^{a}$ & $M_{\mathrm{n}, \mathrm{SEC}}\left(\mathrm{g} \mathrm{mol}^{-1}\right)^{b}$ & $\oplus^{b}$ \\
\hline 1 (PS-Se-1-b-PEGMA 320 ) & 320 & 95.4 & 2700 & 1.09 \\
\hline 2 (PS-Se-1-b-PEGMA 500 ) & 500 & 90.2 & 3200 & 1.09 \\
\hline 3 (PS-Se-1- $b$-PEGMA 950 ) & 950 & 85.0 & 3700 & 1.11 \\
\hline
\end{tabular}

${ }^{a}$ Conversion of PS-Se-1 determined after separation by NMR analysis with reference to TMS as an internal standard.

${ }^{b} Ð$ was determined by SEC (THF as eluent, $1 \mathrm{~mL} \mathrm{~min}^{-1}, 40^{\circ} \mathrm{C}$ ) using polystyrene calibration.

\subsection{Self-Assembly of PS-Se-1-b-PEGMA $A_{950}$ Before and After Oxidation}

Selenium-containing copolymers have shown redox responsiveness in many systems. Some selenide-containing aggregates can respond rapidly to external redox stimuli and subsequently release the incorporated species under mild conditions $[26,28]$. Here, self-assembly behavior of the three copolymers were investigated. It was found that PS-Se-1-b-PEGMA ${ }_{950}$ could self-assemble spontaneously in aqueous solution through hydrophobic/hydrophilic interaction. As shown in Figure 6, the TEM measurement of PS-Se-1-b-PEGMA ${ }_{950}$ micelles showed spherical aggregates with an average diameter of $30 \mathrm{~nm}$. The DLS results are in accordance with the TEM results with an average diameter of $56 \mathrm{~nm}$ (Figure 7a). It is noteworthy that the micelles were quite stable in an ambient environment and could maintain their structures for at least one month. Then, $\mathrm{H}_{2} \mathrm{O}_{2}$ solution was used as the oxidant to study the oxidation responsiveness of the selenide block copolymer aggregates. From the TEM images shown in Figure $6 c, d$, the micellar structure was converted to irregular aggregates after two hours of oxidation process, and these irregular aggregates were further decomposed for another three hours. The DLS results also proved that the morphology change of the aggregates occurred after adding $\mathrm{H}_{2} \mathrm{O}_{2}$ solution. Furthermore, XPS was also used to analyze these micelles before and after oxidation treatment. As shown in Figure $7 \mathrm{~b}$, the binding energy of Se $3 \mathrm{~d}^{5}$ shifts from $56.22 \mathrm{eV}$ to $60.81 \mathrm{eV}$, suggesting a higher valency of selenium which is close to the seleninic acid group [21]. All the results proved that oxidative cleavage of the selenide linkage leads to the morphology change of the micelle.

a)

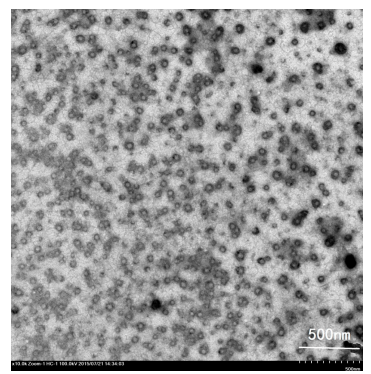

c)

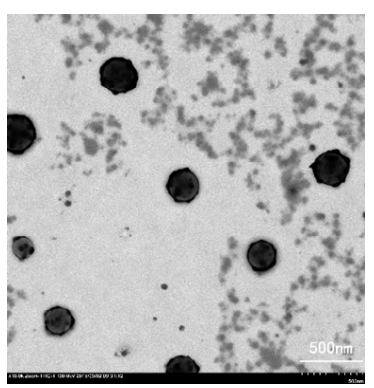

b)

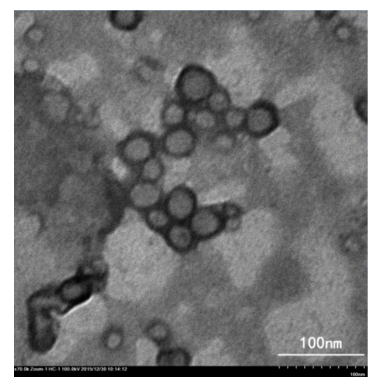

d)

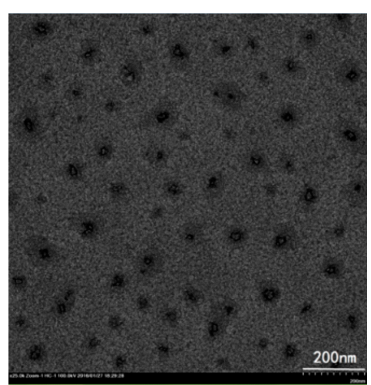

Figure 6. TEM images of self-assembled nanoparticles formed by PS-Se-1- $b$-PEGMA $\left(M_{n, S E C}=3700 \mathrm{~g}\right.$ $\left.\mathrm{mol}^{-1}, \Xi=1.11,1 \times 10^{-4} \mathrm{M}\right)$ at $(\mathbf{a}) \times 10.0 \mathrm{k}$ and $(\mathbf{b}) \times 70.0 \mathrm{k}$ magnification. TEM images of nanoparticles $5 \mathrm{~h}$ after adding $\mathrm{H}_{2} \mathrm{O}_{2}$ solution at $(\mathbf{c}) \times 10.0 \mathrm{k}$ and $(\mathbf{d}) \times 25.0 \mathrm{k}$ magnification. 
a)

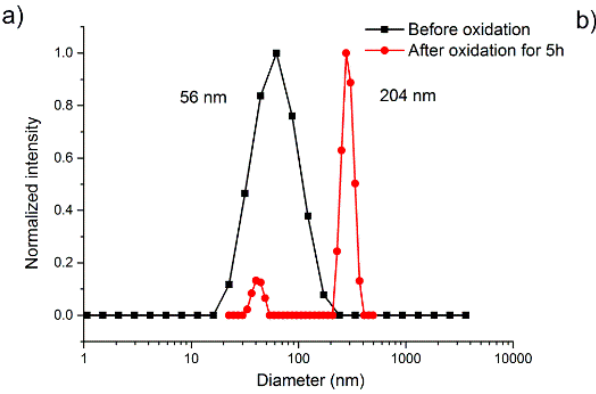

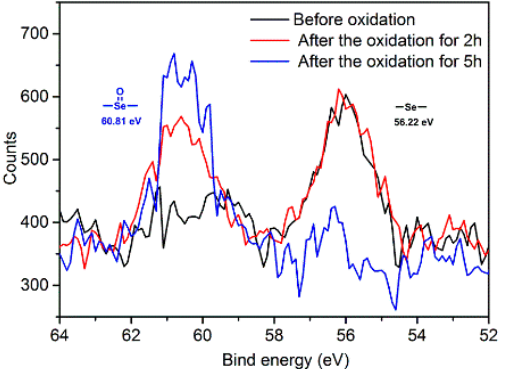

Figure 7. (a) DLS results of PS-Se-1- $b$-PEGMA $\left(M_{\mathrm{n}, S E C}=3700 \mathrm{~g} \mathrm{~mol}^{-1}, \nexists=1.11,1 \times 10^{-4} \mathrm{M}\right)$ assemblies before and after oxidation treatment. (b) XPS analysis of the selenide polymer aggregates before and after oxidation treatment.

\subsection{Cytotoxicity Test}

The nanomicelles based on selenide-labeled amphiphilic copolymers potentially provide a new platform for targeted drug delivery. We examined the cytotoxicity of PS-Se-1- $b$-PEGMA $\left(M_{n, S E C}=\right.$ $\left.3700 \mathrm{~g} \mathrm{~mol}^{-1}, Ð=1.11,1 \times 10^{-4} \mathrm{M}\right)$. As shown in Figure 8, it can be seen that the PS-Se- $b$-PEGMA showed low cytotoxicity when compared with other selenide-containing polymers [40]. The obvious inhibitory effect on the NIH-3T3 cells was shown when the concentration of the micelles was high, at up to $1.6 \mathrm{mg} \mathrm{mL}^{-1}$.

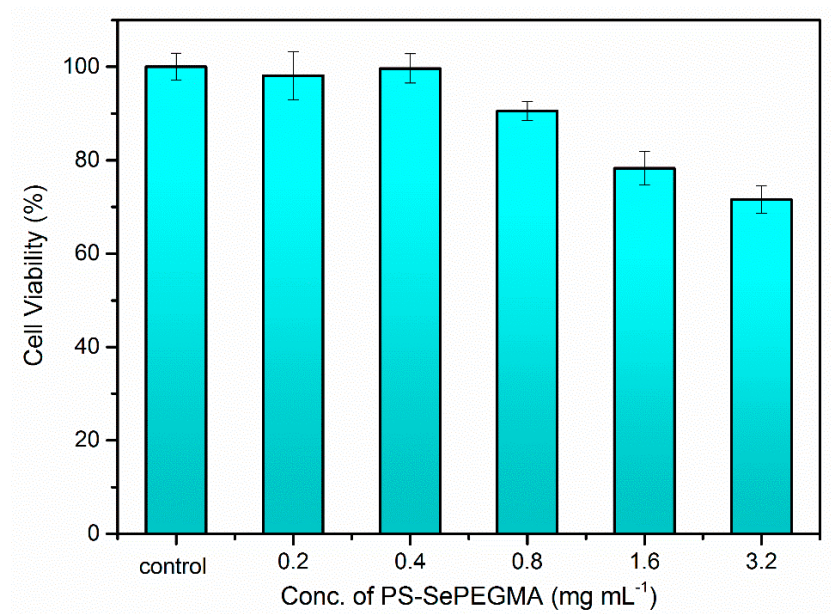

Figure 8. Cytotoxicity of PS-Se- $b$-PEGMA $\left(M_{\mathrm{n}, \mathrm{SEC}}=3700 \mathrm{~g} \mathrm{~mol}^{-1}, Ð=1.11\right)$ at different concentrations. The data are expressed as mean $\pm S D$, where $n=3$.

\subsection{Drug Loading and Oxidation-Responsive Drug Release}

The anticancer drug doxorubicin (DOX) was chosen as a model molecule for encapsulation. The self-assembly of PS-Se-1- $b$-PEGMA $950\left(1 \mathrm{mg} \mathrm{mL}^{-1}\right)$ was conducted in DMF solution in the presence of DOX $\left(0.1 \mathrm{mg} \mathrm{mL}^{-1}\right)$, which has a characteristic maximum emission at $590 \mathrm{~nm}$. The DOX-loading micelles were purified with dialysis membrane, and the DOX concentration was calculated by the fluorescence emission spectra. The drug loading content (DLC) was evaluated to be about $1.5 \%$, and drug loading efficiency (DLE) was evaluated to be about 13.3\%. Oxidation-triggered drug release studies in vitro were investigated at $\mathrm{pH} 7.4$ and $25^{\circ} \mathrm{C}$ by using $\mathrm{H}_{2} \mathrm{O}_{2}$. After oxidation for a specific time, the fluorescence emission of DOX was monitored, as shown in Figure 9a. The fluorescence intensity of DOX at $590 \mathrm{~nm}$ increased gradually, owing to the release of hydrophobic DOX from the drug carriers. The percentage release was calculated based on the fluorescence changes at $590 \mathrm{~nm}$. The percentage release profile was plotted as a function of time, as shown in Figure $9 b$. 
a)

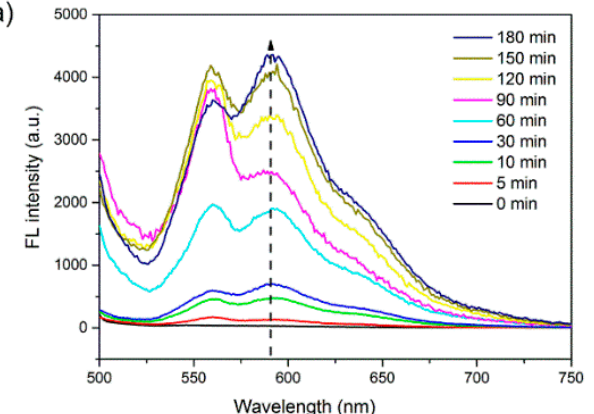

b)

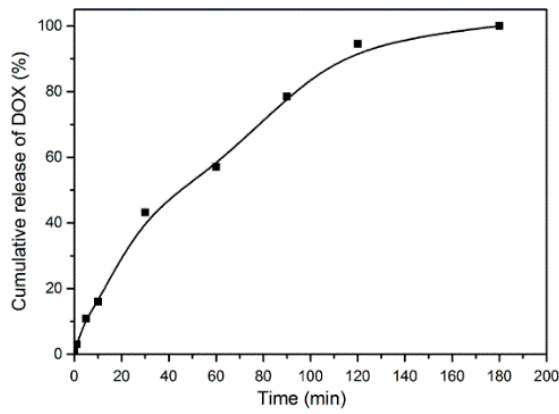

Figure 9. (a) Fluorescence (FL) spectra of the micelles in PBS solution upon treatment with $\mathrm{H}_{2} \mathrm{O}_{2}$ (33 $\mathrm{mM}$ ). (b) Cumulative doxorubicin (DOX) release from DOX-loaded PS-Se-1- $b$-PEGMA950 micelles.

\section{Conclusions}

In conclusion, a straightforward protocol for the synthesis of an oxidation-sensitive selenide-containing block copolymer has been developed on the basis of Se-RAFT. The diselenocarbonate termini of the polymers were readily converted to the selenide-containing block copolymer via aminolysis and selenol-based nucleophilic reaction. The present controlled radical polymerization (CRP)-based protocol offers a facile and straightforward fabrication of selenide-containing block copolymers that feature many monomer accessibilities, predictable MWs, and programmable polymeric architectures. These copolymers formed micelle-like nanoparticles of $\sim 56 \mathrm{~nm}$ in diameter that show insignificant cytotoxicity of the micelles at high concentration and could be disrupted by $\mathrm{H}_{2} \mathrm{O}_{2}$. The biocompatibility and targeted cytotoxicity results suggest that these oxidation-sensitive selenide-containing block copolymers could be developed for controllable drug release.

Author Contributions: X.A. and W.L. performed the experiments; J.Z. analyzed the data and revised the manuscript; X.P. conceived and designed the experiments; X.Z. provided suggestion for the designing of experiments.

Funding: This research was funded by the National Natural Science Foundation of China (nos. 21074082, 21302132, and 21874200), the Natural Science Foundation of Jiangsu Province (BK20130296), the Natural Science Foundation of the Jiangsu Higher Education Institutions of China (no. 12KJB150021), the Priority Academic Program Development of Jiangsu Higher Education Institutions, and the Suzhou Key Lab of Macromolecular Design and Precision Synthesis.

Conflicts of Interest: The authors declare no conflict of interest.

\section{References}

1. Wirth, T. Organoselenium Chemistry: Modern Developments in ORGANIC Synthesis; Springer: Berlin, Germany, 2000; Volume 208.

2. Xia, J.H.; Li, T.Y.; Lu, C.J.; Xu, H.P. Selenium-Containing Polymers: Perspectives toward Diverse Applications in Both Adaptive and Biomedical Materials. Macromolecules 2018, 51, 7435-7455. [CrossRef]

3. Xu, H.P.; Cao, W.; Zhang, X. Selenium-Containing Polymers: Promising Biomaterials for Controlled Release and Enzyme Mimics. Acc. Chem. Res. 2013, 46, 1647-1658. [CrossRef]

4. Nketia-Yawson, B.; Jung, A.R.; Nguyen, H.D.; Lee, K.K.; Kim, B.; Noh, Y.Y. Difluorobenzothiadiazole and Selenophene-Based Conjugated Polymer Demonstrating an Effective Hole Mobility Exceeding $5 \mathrm{~cm}(2) \mathrm{V}-1$ s(-1) with Solid-State Electrolyte Dielectric. ACS Appl. Mater. Interfaces 2018, 10, 32492-32500. [CrossRef]

5. Liang, Z.Q.; Li, M.M.; Zhang, X.M.; Wang, Q.; Jiang, Y.; Tian, H.K.; Geng, Y.H. Near-infrared absorbing non-fullerene acceptors with selenophene as pi bridges for efficient organic solar cells. J. Mater. Chem. A 2018, 6, 8059-8067. [CrossRef]

6. Kim, H.S.; Song, E.; Lee, S.B.; Kang, I.N.; Cho, K.; Hwang, D.H. Effect of methyl substitution on the diketopyrrolopyrrole-based semiconducting polymers for organic thin film transistors. Org. Electron. 2018, 56, 129-138. [CrossRef] 
7. Xu, Z.J.; Shi, G.Z.; Yuan, J.Y.; Glenn, E.; Wang, H.Q.; Ma, W.L. New Semiconducting Polymer Based on Benzo[1,2-b:4,5-b']diselenophene Donor and Diketopyrrolopyrrole/Isoindigo Acceptor Unit: Synthesis, Characterization and Photovoltaics. Chin. J. Chem. 2015, 33, 909-916. [CrossRef]

8. Ashraf, R.S.; Meager, I.; Nikolka, M.; Kirkus, M.; Planells, M.; Schroeder, B.C.; Holliday, S.; Hurhangee, M.; Nielsen, C.B.; Sirringhaus, H.; et al. Chalcogenophene Comonomer Comparison in Small Band Gap Diketopyrrolopyrrole-Based Conjugated Polymers for High-Performing Field-Effect Transistors and Organic Solar Cells. J. Am. Chem. Soc. 2015, 137, 1314-1321. [CrossRef]

9. Kang, I.; An, T.K.; Hong, J.A.; Yun, H.J.; Kim, R.; Chung, D.S.; Park, C.E.; Kim, Y.H.; Kwon, S.K. Effect of Selenophene in a DPP Copolymer Incorporating a Vinyl Group for High-Performance Organic Field-Effect Transistors. Adv. Mater. 2013, 25, 524-528. [CrossRef]

10. Chang, H.H.; Tsai, C.E.; Lai, Y.Y.; Liang, W.W.; Hsu, S.L.; Hsu, C.S.; Cheng, Y.J. A New Pentacyclic Indacenodiselenophene Arene and Its Donor-Acceptor Copolymers for Solution-Processable Polymer Solar Cells and Transistors: Synthesis, Characterization, and Investigation of Alkyl/Alkoxy Side-Chain Effect. Macromolecules 2013, 46, 7715-7726. [CrossRef]

11. Lee, W.H.; Son, S.K.; Kim, K.; Lee, S.K.; Shin, W.S.; Moon, S.J.; Kang, I.N. Synthesis and Characterization of New Selenophene-Based Donor-Acceptor Low-Bandgap Polymers for Organic Photovoltaic Cells. Macromolecules 2012, 45, 1303-1312. [CrossRef]

12. Khim, D.; Lee, W.H.; Baeg, K.J.; Kim, D.Y.; Kang, I.N.; Noh, Y.Y. Highly stable printed polymer field-effect transistors and inverters via polyselenophene conjugated polymers. J. Mater. Chem. 2012, 22, 12774-12783. [CrossRef]

13. Ji, S.B.; Cao, W.; Yu, Y.; Xu, H.P. Visible-Light-Induced Self-Healing Diselenide-Containing Polyurethane Elastomer. Adv. Mater. 2015, 27, 7740-7745. [CrossRef]

14. Ji, S.B.; Fan, F.Q.; Sun, C.X.; Yu, Y.; Xu, H.P. Visible Light-Induced Plasticity of Shape Memory Polymers. ACS Appl. Mater. Interfaces 2017, 9, 33169-33175. [CrossRef]

15. Du, W.N.; Jin, Y.; Lai, S.Q.; Shi, L.J.; Fan, W.H.; Pan, J.Z. Near-infrared light triggered shape memory and self-healable polyurethane/ functionalized graphene oxide composites containing diselenide bonds. Polymer 2018, 158, 120-129. [CrossRef]

16. An, X.W.; Aguirresarobe, R.H.; Irusta, L.; Ruiperez, F.; Matxain, J.M.; Pan, X.Q.; Aramburu, N.; Mecerreyes, D.; Sardon, H.; Zhu, J. Aromatic diselenide crosslinkers to enhance the reprocessability and self-healing of polyurethane thermosets. Polym. Chem. 2017, 8, 3641-3646. [CrossRef]

17. Hailemeskel, B.Z.; Addisu, K.D.; Prasannan, A.; Mekuria, S.L.; Kao, C.Y.; Tsai, H.C. Synthesis and characterization of diselenide linked poly(ethylene glycol) nanogel as multi-responsive drug carrier. Appl. Surf. Sci. 2018, 449, 15-22. [CrossRef]

18. Han, P.; Ma, N.; Ren, H.F.; Xu, H.P.; Li, Z.B.; Wang, Z.Q.; Zhang, X. Oxidation-Responsive Micelles Based on a Selenium-Containing Polymeric Superamphiphile. Langmuir 2010, 26, 14414-14418. [CrossRef]

19. Huang, Y.K.; Chen, Q.X.; Lu, H.G.; An, J.X.; Zhu, H.J.; Yan, X.J.; Li, W.; Gao, H. Near-infrared AIEgen-functionalized and diselenide-linked oligo-ethylenimine with self-sufficing ROS to exert spatiotemporal responsibility for promoted gene delivery. J. Mater. Chem. B 2018, 6, 6660-6666. [CrossRef]

20. Salma, S.A.; Patil, M.P.; Kim, D.W.; Le, C.M.Q.; Ahn, B.H.; Kim, G.D.; Lim, K.T. Near-infrared light-responsive, diselenide containing core-cross-linked micelles prepared by the Diels-Alder click reaction for photocontrollable drug release application. Polym. Chem. 2018, 9, 4813-4823. [CrossRef]

21. Sun, T.B.; Zhu, C.Z.; Xu, J. Multiple stimuli-responsive selenium-functionalized biodegradable starch-based hydrogels. Soft Matter 2018, 14, 921-926. [CrossRef]

22. Xia, J.H.; Ji, S.B.; Xu, H.P. Diselenide covalent chemistry at the interface: Stabilizing an asymmetric diselenide-containing polymer via micelle formation. Polym. Chem. 2016, 7, 6708-6713. [CrossRef]

23. Salma, S.A.; Le, C.M.Q.; Kim, D.W.; Cao, X.T.; Jeong, Y.T.; Lim, K.T. Synthesis and characterization of diselenide crosslinked polymeric micelles via Diels-Alder click reaction. Mol. Cryst. Liq. Cryst. 2018, 662, 188-196. [CrossRef]

24. Kroll, H.; Bolton, E.F. Synthesis of Selenium Condensation Polymers Using Bis(2-Hydroxyethyl) Selenide and Bis(2-Aminoethyl) Selenide. J. Appl. Polym. Sci. 1970, 14, 2319-2325. [CrossRef]

25. Tuten, B.T.; Bloesser, F.R.; Marshall, D.L.; Michalek, L.; Schmitt, C.W.; Blanksby, S.J.; Barner-Kowollik, C. Polyselenoureas via Multicomponent Polymerizations Using Elemental Selenium as Monomer. ACS Macro Lett. 2018, 7, 898-903. [CrossRef] 
26. Ma, N.; Li, Y.; Ren, H.F.; Xu, H.P.; Li, Z.B.; Zhang, X. Selenium-containing block copolymers and their oxidation-responsive aggregates. Polym. Chem. 2010, 1, 1609-1614. [CrossRef]

27. Gunther, W.H.H.; Salzman, M.N. Methods in Selenium Chemistry 4. Synthetic Approaches to Polydiselenides. Ann. NY Acad. Sci. 1972, 192, 25-43. [CrossRef] [PubMed]

28. Ma, N.; Li, Y.; Xu, H.P.; Wang, Z.Q.; Zhang, X. Dual Redox Responsive Assemblies Formed from Diselenide Block Copolymers. J. Am. Chem. Soc. 2010, 132, 442-443. [CrossRef]

29. Chiefari, J.; Chong, Y.K.; Ercole, F.; Krstina, J.; Jeffery, J.; Le, T.P.T.; Mayadunne, R.T.A.; Meijs, G.F.; Moad, C.L.; Moad, G.; et al. Living free-radical polymerization by reversible addition-fragmentation chain transfer: The RAFT process. Macromolecules 1998, 31, 5559-5562. [CrossRef]

30. Kwon, T.S.; Takagi, K.; Kunisada, H.; Yuki, Y. Synthesis of star polystyrene by radical polymerization with 1,2,4,5-tetrakis(p-tert-butylphenylselenomethyl)benzene as a novel photoiniferter. Eur. Polym. J. 2003, 39, 1437-1441. [CrossRef]

31. Zeng, J.D.; Zhu, J.; Zhang, Z.B.; Pan, X.Q.; Zhang, W.; Cheng, Z.P.; Zhu, X.L. New Selenium-Based Iniferter Agent for Living Free Radical Polymerization of Styrene Under UV Irradiation. J. Polym. Sci. Part A Polym. Chem. 2012, 50, 2211-2218. [CrossRef]

32. Keddie, D.J. A guide to the synthesis of block copolymers using reversible-addition fragmentation chain transfer (RAFT) polymerization. Chem. Soc. Rev. 2014, 43, 496-505. [CrossRef] [PubMed]

33. Gao, F.; Pan, X.Q.; Zhu, J.; Zhang, Z.B.; Zhang, W.; Zhu, X.L. Facile synthesis of well-defined redox responsive diselenide-labeled polymers via organoselenium-mediated CRP and aminolysis. Polym. Chem. 2015, 6, 1367-1372. [CrossRef]

34. Cai, Z.X.; Lu, W.H.; Gao, F.; Pan, X.Q.; Zhu, J.; Zhang, Z.B.; Zhu, X.L. Diselenide-Labeled Cyclic Polystyrene with Multiple Responses: Facile Synthesis, Tunable Size, and Topology. Macromol. Rapid Commun. 2016, 37, 865-871. [CrossRef] [PubMed]

35. Wei, C.; Zhang, Y.; Yan, B.K.; Du, Z.Z.; Lang, M.D. A Versatile Strategy to Main Chain Sulfur/Selenium-Functionalized Polycarbonates by Macro-Ring Closure of Diols and Subsequent Ring-Opening Polymerization. Chem. Eur. J. 2018, 24, 789-792. [CrossRef] [PubMed]

36. Pan, X.Q.; Driessen, F.; Zhu, X.L.; Du Prez, F.E. Selenolactone as a Building Block toward Dynamic Diselenide-Containing Polymer Architectures with Controllable Topology. ACS Macro Lett. 2017, 6, 89-92. [CrossRef]

37. Wei, C.; Xu, Y.; Yan, B.K.; Hou, J.Q.; Du, Z.Z.; Lang, M.D. Well-Defined Selenium-Containing Aliphatic Polycarbonates via Lipase-Catalyzed Ring-Opening Polymerization of Selenic Macrocyclic Carbonate Monomer. ACS Macro Lett. 2018, 7, 336-340. [CrossRef]

38. Zeng, J.D.; Zhu, J.; Pan, X.Q.; Zhang, Z.B.; Zhou, N.C.; Cheng, Z.P.; Zhang, W.; Zhu, X.L. Organoselenium compounds: Development of a universal "living" free radical polymerization mediator. Polym. Chem. 2013, 4, 3453-3457. [CrossRef]

39. Lu, W.H.; An, X.W.; Gao, F.; Zhu, J.; Zhou, N.C.; Zhang, Z.B.; Pan, X.Q.; Zhu, X.L. Highly Efficient Chain End Derivatization of Selenol-Ended Polystyrenes by Nucleophilic Substitution Reactions. Macromol. Chem. Phys. 2017, 218, 1600485. [CrossRef]

40. Zhou, W.; Wang, L.; Li, F.; Zhang, W.; Huang, W.; Huo, F.; Xu, H.P. Selenium-Containing Polymer@Metal-Organic Frameworks Nanocomposites as an Efficient Multiresponsive Drug Delivery System. Adv. Funct. Mater. 2017, 27, 1605465. [CrossRef]

(C) 2019 by the authors. Licensee MDPI, Basel, Switzerland. This article is an open access article distributed under the terms and conditions of the Creative Commons Attribution (CC BY) license (http://creativecommons.org/licenses/by/4.0/). 